\title{
Options for COVID-19 Entry into Pulmonary Cells
}

\author{
Kristina I Boström ${ }^{1,2 *}$ and Yucheng Yao*1 \\ ${ }^{1}$ Division of Cardiology, David Geffen School of Medicine at UCLA, Los Angeles, CA 90095-1679, USA \\ ${ }^{2}$ The Molecular Biology Institute at UCLA, Los Angeles, CA 90095-1570, USA
}

*Corresponding authors: Kristina I Boström, Division of Cardiology, David Geffen School of Medicine at UCLA, Los Angeles, CA 90095-1679, U.S.A; The Molecular Biology Institute at UCLA, Los Angeles, CA 90095-1570, U.S.A

Yucheng Yao, Division of Cardiology, David Geffen School of Medicine at UCLA, Los Angeles, CA 90095-1679, U.S.A

\begin{tabular}{|c|c|}
\hline ARTICLE INFO & ABSTRACT \\
\hline Received: July 23, 2020 & \multirow{2}{*}{$\begin{array}{l}\text { Citation: Kristina I Boström, Yucheng Yao. Options for COVID-19 Entry into Pulmonary } \\
\text { Cells. Biomed J Sci \& Tech Res 29(2)-2020. BJSTR. MS.ID.004781. }\end{array}$} \\
\hline Published: August 05, 2020 & \\
\hline
\end{tabular}

\section{Mini Review}

Seven billion people all over the world are currently threatened by the Coronavirus Disease 2019 (COVID-19) virus, and the scientific community has been mobilized to the best of its ability to counteract this threat. Here we consider it to be essential to highlight certain contradictions in COVID-19-related studies on the Angiotensin Converting Enzyme 2 (ACE2) that have been performed so far. Although ACE2 has been reported as the main mechanism of COVID-19 for entry into pulmonary cells, a careful review of the literature and publicly available data sets suggest this may not be the only or even the main mechanism for entry of COVID-19 into pulmonary cells.

As scientists around the world are trying to counteract the spread of COVID-19, the mechanism underlying the entry of the virus into pulmonary cells has become a critical and hot topic $[1,2]$. The ACE2 protein was previously identified as a receptor for the virus [3]. However, when we examined the levels of the ACE2 transcript and the corresponding protein using the Human Protein Atlas search engine [4], we found extremely low levels of both transcript and protein in the lung tissues. The results were confirmed by data extracted from four different publicly available expression data sets, including those from Consensus, HPA, GTEx and FANTOM5. We also examined the ACE2 expression at the single-cell resolution by searching two data sets of single-cell RNAsequencing (scRNA-seq) of the entire lung cell population in mouse and human [5,6]. The results showed that the expression of ACE2 was undetectable in the various subtypes of pulmonary cells. This makes it difficult to understand how such a low level of ACE2 allows COVID-19 to enter the pulmonary cells and cause enormous injury to most of the cellular subtypes [7].
During the search process, as would be expected, we found that ACE2 was highly expressed in kidney tissues and kidney epithelial cells. This finding directed us to review how the interaction between COVID-19 and ACE2 was identified. ACE2 was first reported as the receptor for SARS-CoV by the research groups of Drs. Hyeryun Choe and Michael Farzan [3], who used 293T and Vero E6 as cell models [3]. Subsequently, the hypothesis that cell entry of SARS-CoV was mediated by ACE2 was extensively tested in these two cell types [8,9]. Since 293T and Vero E6 are kidney-derived cell lines, it is not surprising to find high expression of ACE2 to interact with SARS$\mathrm{CoV}$ [3]. However, in the pulmonary cells, it might be a different story because of the almost undetectable ACE2 expression.

Recently, more detailed examinations of ACE2 expression in lung tissue and pulmonary epithelial cells was reported in two excellent studies $[10,11]$. In these reports, ACE2 was expressed in less than $1 \%$ of the pulmonary cells $[10,11]$. Specifically, ACE2 was expressed in bronchiolar club cells, but not at all or at an extremely low level in ciliated cells $[10,11]$. In contrast, a high density of COVID-19 virus particles was found in the ciliated cells, where the COVID-19 virus also replicated [7]. The results suggest that the cells without ACE2 also can be infected by COVID-19.

Thus, the interaction between ACE2 and COVID-19 is well supported to be a potential mechanism for virus entry into ACE2enriched cells such as kidney cells. However, it is still questionable if the same mechanism is used by the virus in pulmonary cells. The PubMed search engine identified only 57 published articles when searching for "ACE2 pulmonary epithelial cells", as compared to 2006 articles when the search term "ACE" was used. Unfortunately, 
none of the 57 studies used pulmonary cells as models for their investigations of SARS-CoV or COVID-19.

The strongest evidence of ACE2-mediated entry of SARS-CoV into pulmonary cells was obtained from ACE2 knockout mice [12]. Based on the infection and replication of SARS-CoV in the respiratory tracts of mice [13], the study showed lower collective titers of SARS-CoV in ACE2 knockout mice than in wild type mice after infection [12]. However, wild type mice exhibited mild lung injuries after infection with extremely high titers of SARS-CoV collected from lungs [12]. The studies brought into question the specificity of viral infection across different species and suggested that mouse ACE2 mediated the entry of SARS-CoV into the pulmonary cells, even though its expression was extremely low. This study contradicted a very recent study, which showed that mouse recombinant soluble ACE2 had no effect on SARS-CoV-2 infection in Vero E6 cells, whereas human recombinant soluble ACE2 prevented infection [14]. The results indicated that mouse ACE2 could not even bind to SARS-CoV-2 [14].

Thus, there is evidence of an interaction between ACE2 and SARS-CoV or COVID-19, and human soluble ACE2 might be a useful treatment to neutralize the virus binding. However, it is still questionable if ACE2 is the receptor for COVID-19 that mediates the entry into the lung cells. Indeed, a study that took advantage of a pulmonary cell cDNA library identified CD209L as another SARS$\mathrm{CoV}$ binding protein, but detailed experiments supporting this as a viral entry point were not performed [15]. In all, we expect that additional studies on alternative entry points of COVID-19 will be available in the near future and able to sort out these important discrepancies in the search for viable treatment strategies.

\section{Acknowledgment}

Funding for this work was provided in part by NIH grants NS79353 (Y.Y.), HL139675 (Y.Y.), HL30568 (K.I.B.), and HL81397 (K.I.B.).

\section{Competing Financial Interests}

The authors have declared that no conflict of interest exists.

\section{References}

1. Carvalho T (2020) COVID-19 Research in Brief: 4 April to 10 April, 2020. Nat Med.

ISSN: 2574-1241

DOI: $10.26717 / B J S T R .2020 .29 .004781$

Kristina I Boström. Biomed J Sci \& Tech Res

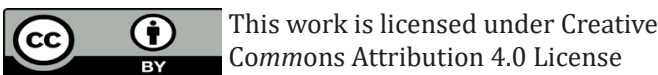

Submission Link: https://biomedres.us/submit-manuscript.php
2. Haffajee RL, Mello MM (2020) Thinking Globally, Acting Locally - The U.S. Response to Covid-19. N Engl J Med 382(22): e75.

3. Li W, Moore MJ, Vasilieva N, Sui J, Wong SK, et al. (2003) Angiotensinconverting enzyme 2 is a functional receptor for the SARS coronavirus. Nature 426(6965): 450-454.

4. Uhlen M, Fagerberg L, Hallstrom BM, Lindskog C, Oksvold P, et al. (2015) Proteomics. Tissue-based map of the human proteome. Science 347(6220): 1260419

5. Morse C, Tabib T, Sembrat J, Buschur KL, Bittar HT, et al. (2019) Proliferating SPP1/MERTK-expressing macrophages in idiopathic pulmonary fibrosis. Eur Respir J 54(2): 1802441.

6. Tabula Muris C, Overall C, Logistical C, Organ C, processing, et al. (2018) Single-cell transcriptomics of 20 mouse organs creates a Tabula Muris. Nature 562(7727): 367-372.

7. Zhu N, Zhang D, Wang W, Li X, Yang B, et al. (2020) A Novel Coronavirus from Patients with Pneumonia in China, 2019. N Engl J Med 382(8): 727733.

8. Simmons G, Gosalia DN, Rennekamp AJ, Reeves JD, Diamond SL, et al. (2005) Inhibitors of cathepsin L prevent severe acute respiratory syndrome coronavirus entry. Proc Natl Acad Sci U S A 102(33): 1187611881.

9. Wang H, Yang P, Liu K, Guo F, Zhang Y, et al. (2008) SARS coronavirus entry into host cells through a novel clathrin- and caveolae-independent endocytic pathway. Cell research 18(2): 290-301.

10. Lukassen S, Chua RL, Trefzer T, Kahn NC, Schneider MA, et al. (2020) SARS-CoV-2 receptor ACE2 and TMPRSS2 are primarily expressed in bronchial transient secretory cells. EMBO J 39(10): e105114.

11. Sungnak W, Huang N, Becavin C, Berg M, Queen R, et al. (2020) SARSCoV-2 entry factors are highly expressed in nasal epithelial cells together with innate immune genes. Nat Med 6(5): 681-687.

12. Kuba K, Imai Y, Rao S, Gao H, Guo F, et al. (2005) A crucial role of angiotensin converting enzyme 2 (ACE2) in SARS coronavirus-induced lung injury. Nat Med 11(8): 875-879.

13. Subbarao K, Mc Auliffe J, Vogel L, Fahle G, Fischer S, et al. (2004) Prior infection and passive transfer of neutralizing antibody prevent replication of severe acute respiratory syndrome coronavirus in the respiratory tract of mice. J Virol 78(7): 3572-3577.

14. Monteil V, Kwon H, Prado P, Hagelkruys A, Wimmer RA, et al. (2020) Inhibition of SARS-CoV-2 Infections in Engineered Human Tissues Using Clinical-Grade Soluble Human ACE2. Cell 181(4): 905-913 e907.

15. Jeffers SA, Tusell SM, Gillim Ross L, Hemmila EM, Achenbach JE, et al. (2004) CD209L (L-SIGN) is a receptor for severe acute respiratory syndrome coronavirus. Proc Natl Acad Sci U S A 101(4): 15748-15753.

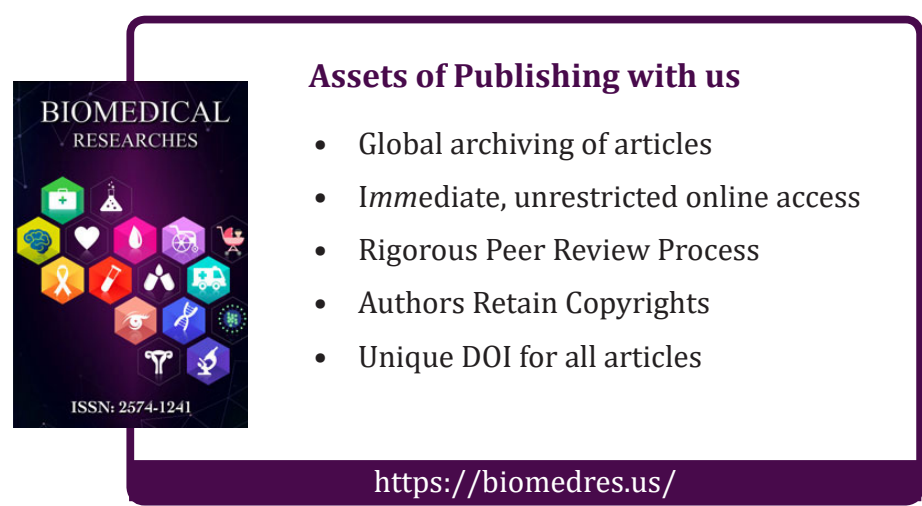

